\title{
Azospirillum Growth Promotion Is Related to Changes in Ferulate and Dehydrodiferulate Contents in Cell Wall of Inoculated Cucumber Seedlings Hypocotyls
}

\author{
Claudia C. Dal Lago, Cecilia M. Creus, M. Alejandra Pereyra* \\ Laboratorio de Bioquímica Vegetal y Microbiana, Unidad Integrada Balcarce, Facultad de Ciencias Agrarias, \\ Universidad Nacional de Mar del Plata, EEA Balcarce INTA, Balcarce, Argentina \\ Email: cdallago@uolsinectis.com.ar, creus.cecilia@inta.gob.ar, ${ }^{*}$ malperey@mdp.edu.ar
}

Received 16 April 2015; accepted 27 June 2015; published 30 June 2015

Copyright (C) 2015 by authors and Scientific Research Publishing Inc.

This work is licensed under the Creative Commons Attribution International License (CC BY). http://creativecommons.org/licenses/by/4.0/

(c) (i) Open Access

\begin{abstract}
Azospirillum brasilense is a well known plant growth-promoting rhizobacterium. Plant cell growth is constrained by the primary cell wall ( $\mathrm{CW}$ ) which contains polysaccharide-bound hydroxycinammic acids (HCAs). They derive from phenylpropanoid metabolism, which first step is the reaction catalyzed by phenylalanine ammonia-lyase (PAL; EC 4.3.1.24). Also CW peroxidases (FAPOD; EC 1.11.1.7) play a key role in the stiffening of the $\mathrm{CW}$, and in the cessation of cell elongation. Knowledge of the biochemical effects the bacteria could elicit into plant $\mathrm{CW}$ and how these responses could change the hypocotyl physiology still remains scarce. The objective of this work was to unravel the effects of $A$. brasilense Sp245 inoculation on HCAs of the primary CW in apical and basal segments of cucumber seedlings hypocotyls. Azospirillum inoculation increased hypocotyls' length. Trans-ferulate and p-coumarate were the major HCAs. Dimmers were detected only in the basal region of 13- and 15-d-old hypocotyls. The ratio t-ferulate/dimmer (an inverse index of CW crosslinking) was five times higher in inoculated seedlings. Enzyme activities determined were not directly involved in HCAs content changes. It was previously reported that the CW was a target for $A$. brasilense growth promotion. This work corroborates that the phenolics, FA, DFA, and p-coumarate bound to the CW are also involved in Azospirillum plant growth promoting strategies.
\end{abstract}

\section{Keywords}

Azospirillum, Plant Growth Promotion, Plant Cell Wall, Hydroxycinammic Acids

${ }^{*}$ Corresponding author.

How to cite this paper: Dal Lago, C.C., Creus, C.M. and Pereyra, M.A. (2015) Azospirillum Growth Promotion Is Related to Changes in Ferulate and Dehydrodiferulate Contents in Cell Wall of Inoculated Cucumber Seedlings Hypocotyls. American Journal of Plant Sciences, 6, 1650-1661. http://dx.doi.org/10.4236/ajps.2015.610165 


\section{Introduction}

Several mechanisms have been postulated to explain how Plant Growth Promoting Rhizobacteria (PGPR) enhance growth and development of plants. Azospirillum represents one of the best characterized free-living diazotrophs among PGPR [1]. It was previously reported that the cell wall (CW) is a target for A. brasilense growth promotion [2]-[4]. Plant cell growth is constrained by the primary CW which consists of cellulosic micro fibrils embedded in a matrix of interwoven non-cellulosic polysaccharides and proteins [5]. In addition to polysaccharides, CW contains minor amounts of phenolic acids [6]. Of these phenolics, ferulate (FA) bound to the CW undergoes a peroxidase-catalyzed coupling reaction to produce dehydrodiferulates (DFA), which crosslinks matrix polysaccharides [7] [8]. Conditions that inhibit growth as well as an advanced developmental stage, may lead to CW tightening via an increase in the number of diferuloyl cross links present [9]. Thus, the levels of CW-bound FA and DFA have been considered to contribute to the rigidity of CW. Numerous studies have demonstrated a correlation between an increase in the content of DFA in CW of gramineous coleoptiles and a decrease in growth and CW extensibility [10]-[12]. By the other side, very small quantities of p-coumarate (another phenolic acid) are esterified to arabinoxylans in immature tissues, and most p-coumarate accretion occurs in tandem with lignification, making p-coumarate accumulation a convenient indicator of lignification [13].

Peroxidases are multifunctional enzymes that can build a rigid CW or produce reactive oxygen species to make it more flexible, depending on two possible catalytic cycles, peroxidative or hydroxylic, respectively [14]. These enzymes are prevalent at every stage of plant growth. In particular, dicots FA peroxidase (FAPOD; EC 1.11.1.7) participates in the oxidative coupling of feruloyl-arabinogalactan side-chains in the presence of $\mathrm{H}_{2} \mathrm{O}_{2}$ [14]. Ferulates are synthesized via the phenylpropanoid pathway, in which phenyl alanine ammonia lyase (PAL; EC 4.3.1.24) catalyzes the first step playing a rate-limiting role in the pathway [15]. The involvement of PAL activity in the regulation of the amount of CW-bound FA has been shown in wheat [11] and maize shoots [16].

Precisely how CW components and their intermolecular interactions are changed to allow CW stiffening during growth cessation is not completely known [17]. Azospirillum inoculation induced higher CW elasticity a biophysical indication of CW induced differences during plant cell elongation [3]. Knowledge of the biochemical effects the bacteria could elicit into plant CW and how these responses could change the hypocotyl physiology still remains scarce. The objective of this work was to analyze whether A. brasilense inoculation affected cucumber (Cucumis sativus) hypocotyl primary CW dynamics. For this purpose, CW-bound FA, DFA and p-coumarate contents, CW-bound FAPOD (against ferulate), and PAL activities were determined in apical (immature expanding cells) and basal (mature non expanding cells) segments of cucumber hypocotyls from dark grown seedlings inoculated with A. brasilense Sp245.

\section{Results}

Root colonization by Azospirillum must be attained in order to promote plant growth. Total A. brasilense cells number per gram of fresh weight (FW) of root tissue was ca. $8 \times 10^{6}$ in all four times determined. In contrast, less than $10^{2}$ bacterial cells $\mathrm{g} \cdot \mathrm{FW}^{-1}$ were detected in non-inoculated controls.

Hypocotyls from A. brasilense-inoculated seedlings were larger than those from non inoculated controls (Figure 1). Nevertheless, growth promotion declined from day 10 on.

At day 8, FA contents were similar in both inoculated and non-inoculated hypocotyls either in apical (Figure 2(b)) or in basal segments (Figure 2(a)) and DFA was not detected (Figure 3). Younger apical tissues showed ca. 6 times lesser FA content than older basal ones (Figure 2(a) and Figure 2(b)).

With respect to basal segments from day 10 to 13 controls showed higher FA contents than A. brasilense inoculated ones. This difference disappeared at day 15 . The only DFA detected in these cucumber tissues was the 8-O-4'-diferulate dimmer and was present in higher quantities in controls than in inoculated segments (Figure 3). Non-inoculated controls showed a sharp increase in FA content until day 13 when it doubled that of day 8 , and coincided with DFA appearance (Figure 2(a) and Figure 3). Both phenolics diminished at day 15 (Figure 2(a) and Figure 3). Instead, A. brasilense inoculated segments showed a less marked increase in FA content at day 13, ca. 35\% from that of day 8 (Figure 2(a)), and although appearing at the same time (day 13) DFA content halved that of the controls (Figure 3). By the other side, p-coumarate content rose to $50 \mathrm{mg} \cdot \mathrm{g} \cdot \mathrm{DW}^{-1}$ in controls at day 13 , and then diminished to $40 \mathrm{mg} \cdot \mathrm{g} \cdot \mathrm{DW}^{-1}$. Instead A. brasilense-inoculated ones reached only 43 $\mathrm{mg} \cdot \mathrm{g} \cdot \mathrm{DW}^{-1}$ at day 13 and then fell to $32 \mathrm{mg} \cdot \mathrm{g} \cdot \mathrm{DW}^{-1}$ (Figure 4(a)). Differences could also be detected in the ratio of FA to DFA (Figure 5). While it remained constant from day 13 to 15 in control segments, it increased 


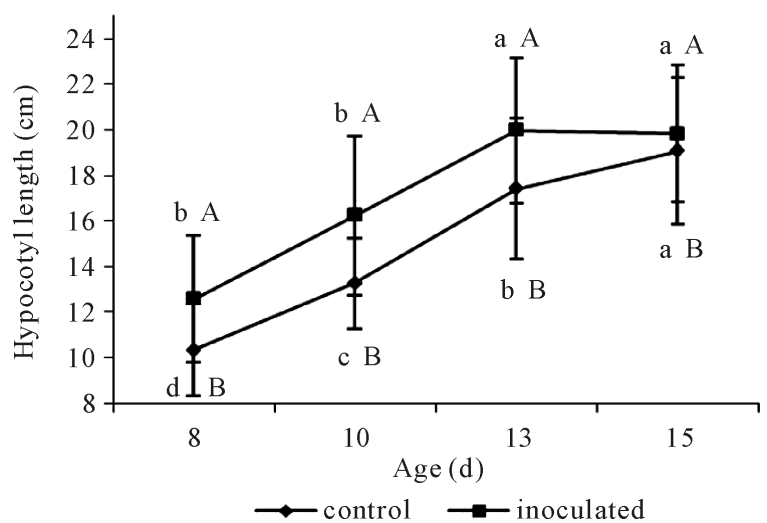

Figure 1. Length of non-inoculated (control) or A. brasilense-inoculated cucumber hypocotyls. Seeds were disinfected and germinated on wet filter paper in sealed trays and incubated in darkness at $25^{\circ} \mathrm{C} \pm 1{ }^{\circ} \mathrm{C}$ for $24 \mathrm{~h}$. Pre-germinated seeds were submerged in a $10^{6}$ Azospirillum cells $\mathrm{mL}^{-1}$ phosphate buffer ( $\mathrm{pH} \mathrm{6.8)} \mathrm{for} 2 \mathrm{~h}$. Controls were treated with $66 \mathrm{mM}$ phosphate buffer (pH 6.8). Seedlings continued growing in darkness at $25^{\circ} \mathrm{C} \pm 1^{\circ} \mathrm{C}$ and samples were taken at days $8,10,13$, and 15 . Results are shown as mean \pm S.D. $(\mathrm{P}<0.05)$, obtained from 150 replicates. Values denoted by different capital letters differ significantly at $\mathrm{P}<0.05$ between inoculated or control treatments. Values denoted by different small letters differ significantly at $\mathrm{P}<0.05$ between sampling times.

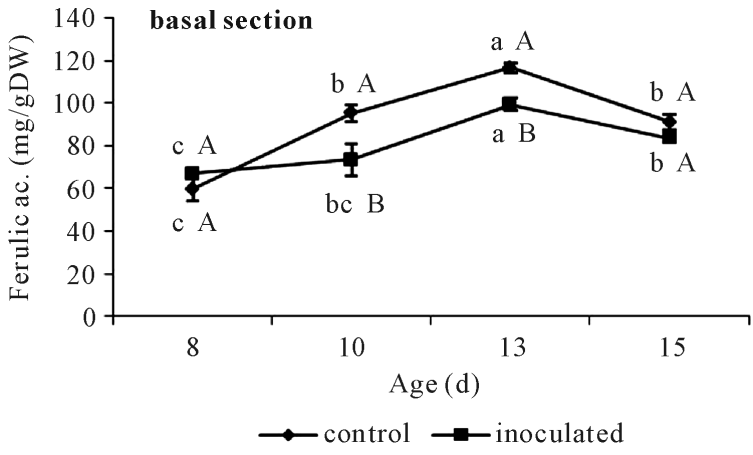

(a)

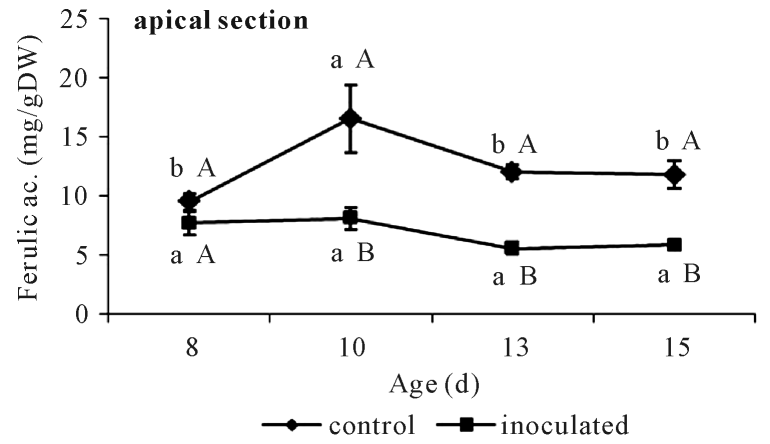

(b)

Figure 2. Ferulate content in non-inoculated (control) or A. brasilense-inoculated cucumber hypocotyls basal (a) or apical (b) segments. Seedlings were grown in darkness at $25^{\circ} \mathrm{C} \pm 1^{\circ} \mathrm{C}$ and samples were taken at days $8,10,13$, and 15 . Results are shown as mean \pm S.D. $(\mathrm{P}<0.05)$ obtained from three replicates of $0.2 \mathrm{~g}$ each. Values denoted by different capital letters differ significantly at $\mathrm{P}<0.05$ between inoculated or control treatments. Values denoted by different small letters differ significantly at $\mathrm{P}<0.05$ between sampling times.

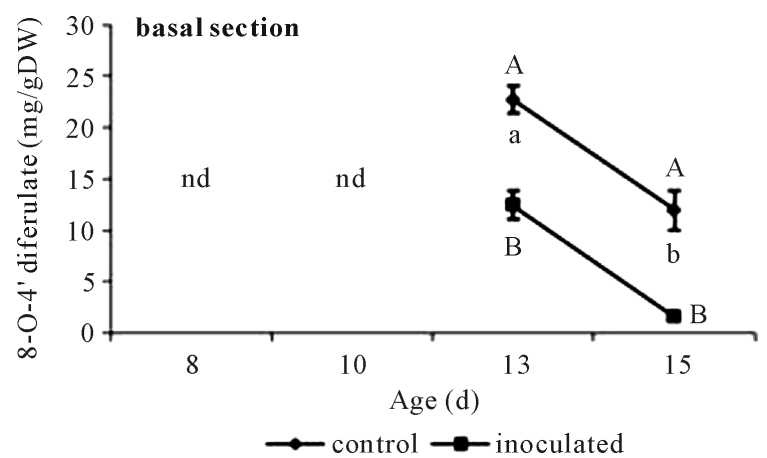

Figure 3. 8-O-4'-diferulate content in basal segments of non-inoculated (control) or A. brasilense-inoculated cucumber hypocotyls. Seedlings were grown in darkness at $25^{\circ} \mathrm{C} \pm 1^{\circ} \mathrm{C}$ and samples were taken at days $8,10,13$, and 15 . Results are shown as mean \pm S.D. $(\mathrm{P}<0.05)$ obtained from three replicates of $0.2 \mathrm{~g}$ each. Values denoted by different capital letters differ significantly at $\mathrm{P}<0.05$ between inoculated or control treatments. Values denoted by different small letters differ significantly at $\mathrm{P}<0.05$ between sampling times. 


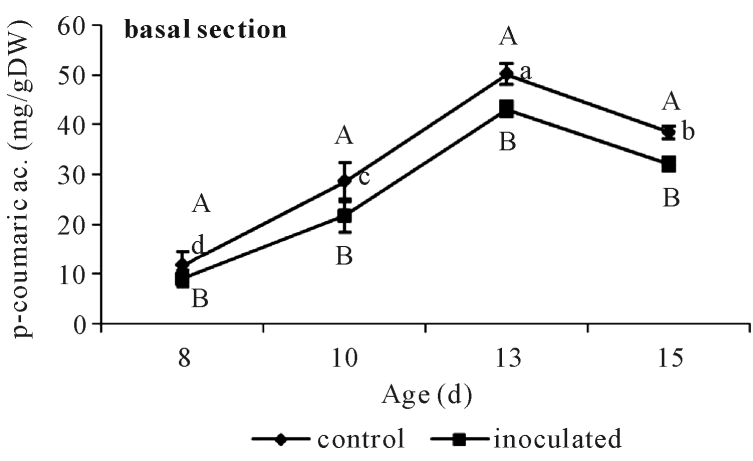

(a)

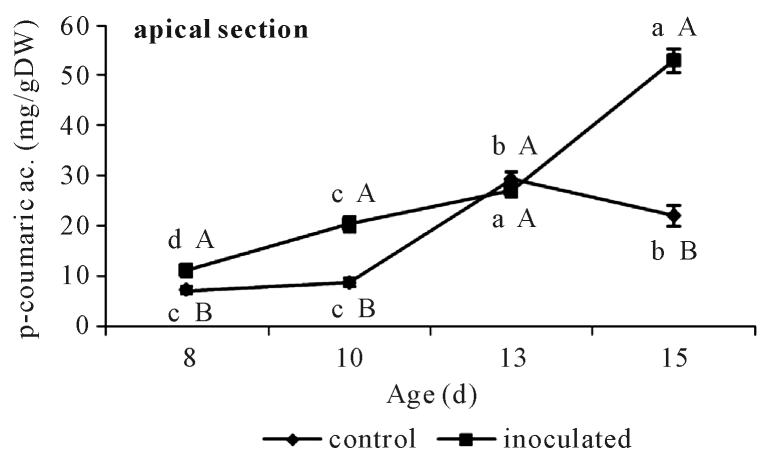

(b)

Figure 4. p-coumarate content in non-inoculated (control) or A. brasilense-inoculated cucumber hypocotyls basal (a) or apical (b) segments. Seedlings were grown in darkness at $25^{\circ} \mathrm{C} \pm 1^{\circ} \mathrm{C}$ and samples were taken at days $8,10,13$, and $15 \mathrm{~d}$. Results are shown as mean \pm S.D. $(\mathrm{P}<0.05)$ obtained from three replicates of $0.2 \mathrm{~g}$ each. Values denoted by different capital letters differ significantly at $\mathrm{P}<0.05$ between inoculated or control treatments. Values denoted by different small letters differ significantly at $\mathrm{P}<0.05$ between sampling times.

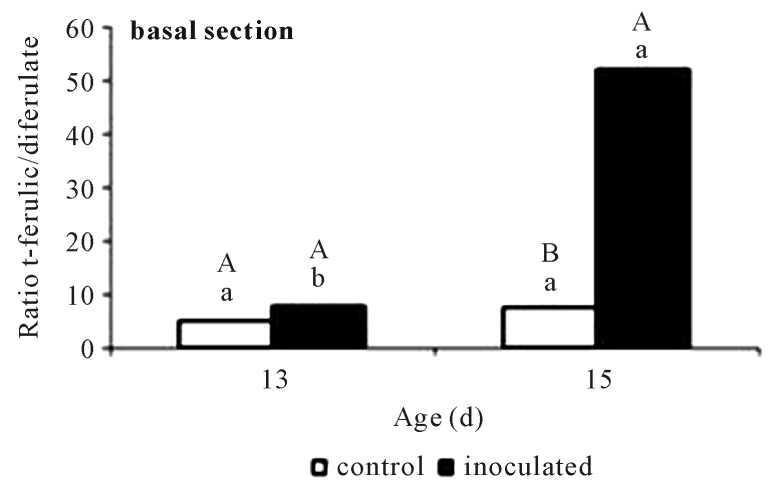

Figure 5. Ratio ferulate to 8-O-4'-diferulate contents in non-inoculated (control) or A. brasilense-inoculated cucumber hypocotyls basal segments. Results obtained at days 13 and 15 are shown as means $(\mathrm{P}<0.05)$ obtained from three replicates. Values denoted by different capital letters differ significantly at $\mathrm{P}<0.05$ between inoculated or control treatments. Values denoted by different small letters differ significantly at $\mathrm{P}<0.05$ between sampling times.

more than five-times in A. brasilense-inoculated ones.

With respect to apical segments from day 10 on, control and A. brasilense inoculated treatments showed different FA contents. Non-inoculated controls showed a sharp increase in FA content at day 10, ca. 50\% more than that from day 8 (Figure 2(b)) and then diminished to this same value (Figure 2(b)). Instead, A. brasilense inoculated segments showed the same lower value during all the sampled period (Figure 2(b)). By the other side, p-coumarate content rose to $30 \mathrm{mg} \cdot \mathrm{g} \cdot \mathrm{DW}^{-1}$ both in controls and in A. brasilense-inoculated segments at day 13. At day 15 its value diminished to $20 \mathrm{mg} \cdot \mathrm{g} \cdot \mathrm{DW}^{-1}$ in control segments but reached the highest value of 50 $\mathrm{mg} \cdot \mathrm{g} \cdot \mathrm{DW}^{-1}$ in A. brasilense-inoculated ones (Figure 4(b)).

In sum, A. brasilense inoculation caused a reduction in the amount of the three phenolics determined, and a raise in the ratio of FA to DFA at day 15 in basal segments. Instead, apical segments showed the same reduction in the content of FA but a marked increase in that of p-coumarate at day 15. No DFA was detected in these segments.

FAPOD activity in basal segments was higher in those from A. brasilense inoculated seedlings (Figure 6(a)) with respect to controls. This activity reached a maximum at day 13 in either treatment that remained constant until day 15. In apical segments no differences were detected through the time or between inoculation treatments (Figure 6(b)).

PAL activity in basal segments showed higher values in A. brasilense-inoculated treatments than in controls, but only at days 8 and 10. The first reached the lowest value at day 13. Instead, the second showed a gradual increase before acquiring the higher value at day 15 (Figure 7(a)). Also A. brasilense inoculated treatments 


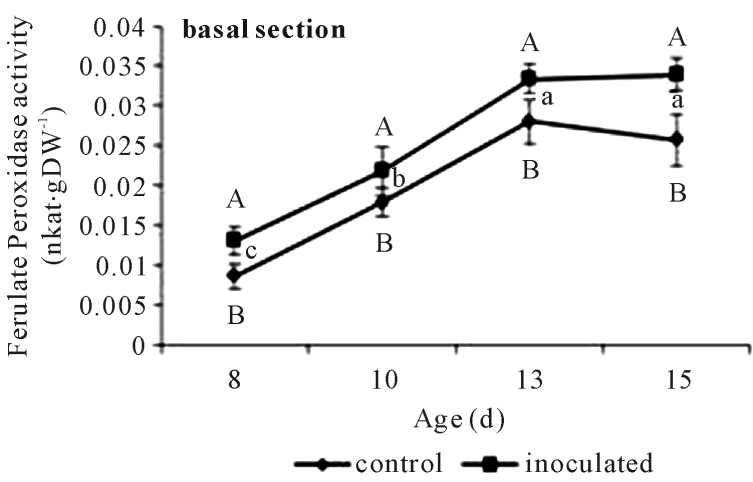

(a)

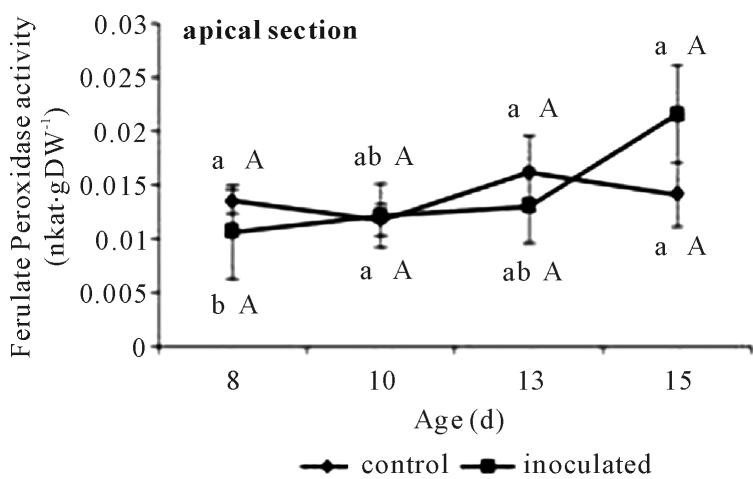

(b)

Figure 6. Cell wall ferulate peroxidase activities assayed against ferulates in non-inoculated (control) or A. brasilenseinoculated cucumber hypocotyls basal (a) or apical (b) segments. Seedlings were grown in darkness at $25^{\circ} \mathrm{C} \pm 1^{\circ} \mathrm{C}$ and samples were taken at days $8,10,13$, and 15 . Ferulate peroxidase activity was measured at $310 \mathrm{~nm}$ and expressed as nkat $\cdot \mathrm{g} \cdot \mathrm{DW}^{-1}$. Results are shown as mean \pm S.D. $(\mathrm{P}<0.05)$ obtained from three replicates of $1 \mathrm{~g}$ each. Values denoted by different capital letters differ significantly at $\mathrm{P}<0.05$ between inoculated or control treatments. Values denoted by different small letters differ significantly at $\mathrm{P}<0.05$ between sampling times.

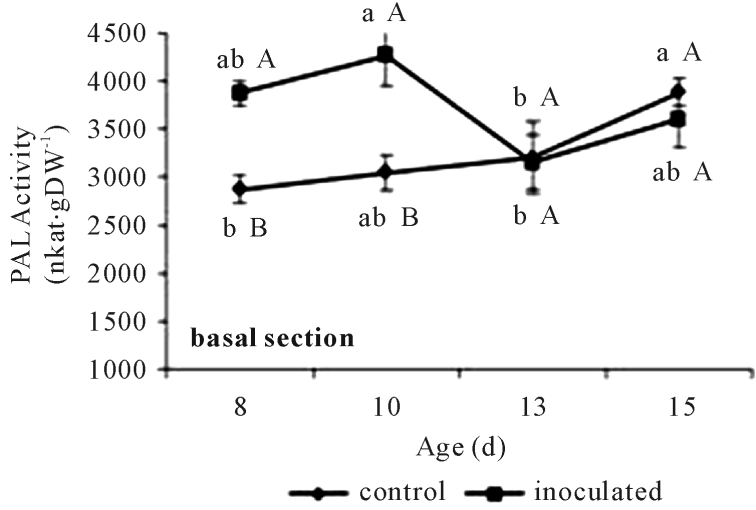

(a)

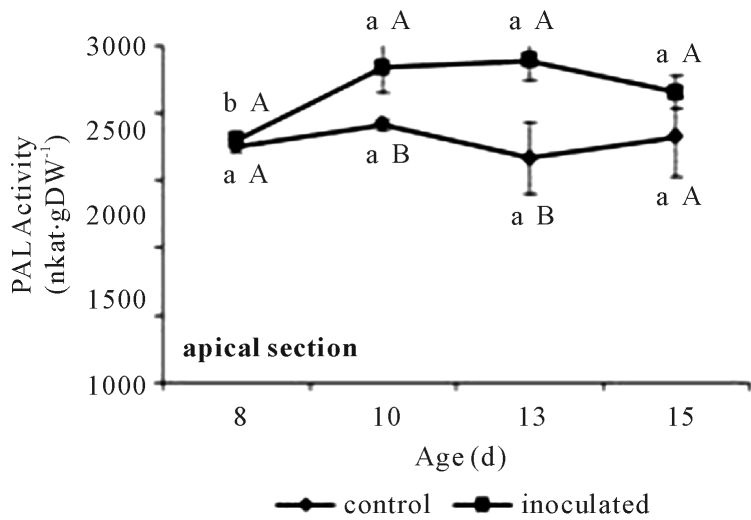

(b)

Figure 7. PAL activities in non-inoculated (control) or A. brasilense-inoculated cucumber hypocotyls basal (a) or apical (b) segments. Seedlings were grown in darkness at $25^{\circ} \mathrm{C} \pm 1^{\circ} \mathrm{C}$ and samples were taken at days $8,10,13$, and 15 . The formation of t-cinnamic acid was measured spectrophotometrically at $290 \mathrm{~nm}$ after $1 \mathrm{~h}$ of incubation of the reaction mixture. PAL activity was expressed as nkat.g. DW ${ }^{-1}$. Results are shown as mean \pm S.D. $(\mathrm{P}<0.05)$, obtained from three replicates of $1 \mathrm{~g}$ each. Values denoted by different capital letters differ significantly at $\mathrm{P}<0.05$ between inoculated or control treatments. Values denoted by different small letters differ significantly at $\mathrm{P}<0.05$ between sampling times.

showed a higher PAL activity in apical segments at days 10 and 13 . This activity remained constant throughout the sampling time in control segments and showed an increase from day 8 to 10 in A. brasilense inoculated ones (Figure 7(b)).

\section{Discussion}

It was reported that $A$. brasilense successfully colonized cucumber roots, stimulated 6-d-old seedling growth, and induced dynamic CW differences between inoculated and non-inoculated hypocotyls [4]. These differences included greater acid-induced CW extension and in vivo elongation when incubated in distilled water, and lower NADH oxidase and FAPOD activities in both young apical segments and basal older ones for Azospirillum inoculated seedlings. It was hypothesized that these lesser activities could be delaying the stiffening of CW in inoculated seedlings accounting for the growth promotion [4]. A higher $\mathrm{CW}$ elasticity in the leaves of A. brasilense inoculated wheat plants was also found [3].

The cross-linkage of polysaccharides by DFA rigidifies the plant CW [6] [7]. Like DFA, CW-bound FA itself 
affects the rigidity of CW [10], possibly by altering the susceptibility of matrix polysaccharides to CW hydrolases [7]. In tissue that is placed into the basal zone of the cucumber hypocotyl, cells are no longer elongating [4] and so CW might be more rigid than in younger apical elongating tissue. To have a clearer picture on the effects of Azospirillum inoculation on the phenolics content of the CW, both kinds of segments were studied independently.

Ferulic acid and DFA contents were first analyzed in a 6-d-old seedlings system. Negligible quantities of FA and none of DFA were found (data not shown). Taking in mind, that seedlings were grown in the dark, and that it is reported that an advanced developmental stage might lead to an increase in the number of DFA cross links present [9], changes in FA and DFA contents in older seedlings were studied. Day 13 was chosen, and detectable quantities of both phenolics were found. So an interval of time from days 8 to 15 after germination was chosen to determine phenolics contents and the activities of their related enzymes.

A. brasilense-inoculated seedlings (ca. $8 \times 10^{6}$ cells $\mathrm{g} \cdot \mathrm{FW}^{-1}$ root tissue) showed larger hypocotyls than noninoculated ones at the four times sampled (Figure 1). Although present, A. brasilense growth promotion declined from day 10 when hypocotyls had reached ca. $16 \mathrm{~cm}$ long, near to the growing cessation stage for etiolated hypocotyles ca. $20 \mathrm{~cm}$ height (data not shown). After emergence of the radicle, the hypocotyl emerges and lifts the growing tip above the ground. Seeds are sowed not deeper than $10 \mathrm{~cm}$ from the soil surface, so starting from the same reserves stored in the seed inoculated seedlings showed ca. a 2-d advantage to find sun light and success, from non-inoculated controls. This effect was also shown for wheat coleoptiles [2].

Results here showed that A. brasilense-inoculation reduced CW FA, DFA and p-coumarate contents in basal segments. Even though the accretion of DFA in CW of basal segments in both inoculation treatments was detected at the same time (day 13) (Figure 3), the accumulation of DFA was lower in A. brasilense-inoculated ones. It is worth to note that although various isomers of DFA might contribute to the natural cross linking of arabinoxylans in vivo, and have been obtained by alkali hydrolysis of CW feruloyl-polysaccharides [18], only the 8-O-4'-diferulate was found in cucumber basal segments. Also, although p-coumarate content reached a maximum value at day 13 in both treatments (Figure 4(a)) it was lower in A. brasilense-inoculated ones.

In studies with monocot coleoptiles [10]-[12], growth dynamics were related not only to CW feruloylation, as indicated by alkali-labile FA and DFA, but also to changes in the ratio between these compounds. In this study, FA/DFA ratio showed the same value for control and A. brasilense-inoculated segments at day 13, at a value of ca. 7:1. That is, A. brasilense treated segments showed the same proportions of FA to DFA although in lesser contents.

Grabber et al. [19] demonstrated that once incorporated into lignin, the three phenolics investigated here are not released from CW by the same room-temperature alkaline hydrolysis used in this work. This fact might explain why their contents dropped from day 13. The highest content of p-coumarate (a convenient indicator of lignification) was reached at this time, and the drop observed in the content of all three phenolics at day 15 might be showing the shifting between primary and secondary wall building. At this point, caution should be exercised when relating FA or DFA concentrations to CW extensibility or growth if lignification of coleoptiles or other tissues has commenced. Results obtained at day 13 (assuming that it was before lignification began) showed that, A. brasilense inoculation caused a reduction in the amounts of the three phenolics determined in basal segments not affecting FA/DFA ratio.

Taking day 15 as the very beginning of lignification, although the three compounds contents fall in both treatments, the FA/DFA ratio raised as high as 50:1 in inoculated segments (Figure 5). This increment was due to a marked DFA reduction (Figure 2(a) and Figure 3) that could be happening because of preferential incorporation of DFA over FA monomers into lignin during secondary wall formation in A. brasilense inoculated segments (day 15). The proportion of FA to DFA might increase due to a more rapid rate of FA deposition than FA dimerization or reach an intermediate level during secondary wall formation [19]. Ferulate and the various DFA isomers also incorporate into lignin at differing rates, altering the apparent abundance and ratio of these p-hydroxycinnamates in CW [19]. The DFA is perceived as a cross-link of the CW [7], but the decrease from day 13 suggested a role for DFA in the enforcement of the CW while it undergoes the transformation from a developing immature CW to the more rigid structure of the mature one [20]. It has been postulated that the proportion of DFA in CW is controlled by different mechanisms, e.g. the unpaired electron distribution of ferulate radicals, the relative energies of the coupling products, matrix effects, and the differing propensity of DFA to co-polymerize into lignin. More investigation should be performed in order to determine the molecular differences between inoculation treatments. 
Apical segments showed ca. 6 times lesser FA content than older basal ones (Figure 2(a) and Figure 2(b)) and DFA was not detected. In these expanding tissues, where FA content is low and DFA is still not present, the A. brasilense induced higher content of p-coumarate might be playing a different role than initiating lignification, perhaps participating in the biosynthesis of other important metabolites like flavonoids [15]. In sum, A. brasilense inoculation also caused a reduction in the amount of FA but an increase in that of p-coumarate in apical segments.

In addition to CW feruloylation, the coupling process of FA catalyzed by CW-bound FAPOD may be closely involved in the regulation of DFA formation [7]. Peroxidases of plants can be divided into two groups; class I peroxidases which use ascorbate as the preferential electron donor and class III peroxidases which use phenolics as the preferential electron donors [21]. Class III peroxidases are localized in vacuoles and in the apoplast (outside of plasma membranes) [14]-[21]. Peroxidases of this class are multifunctional. One such functions, is that of peroxidases in the apoplast that participate in the formation of lignin which deposit in the secondary CW during normal growth [22] [23]. González et al. [24] reported that the DFA formation was preferentially associated to the activity of FAPOD in segments of oat shoots. Also, the addition of hydrogen peroxide stimulated the formation of DFA in CW of maize cell suspensions [8], suggesting that the activation of peroxidases may be involved in the stimulation of DFA formation. In the CW of maize cells grown in suspension culture FA crosslinking requires apoplastic peroxidases and apoplastic $\mathrm{H}_{2} \mathrm{O}_{2}$ [25]. There is evidence that these two factors are important for the in vivo regulation of FA cross-linking in these cells [26]. By the other side, the formation of FA network consists of several biochemical steps. Ferulate itself is synthesized in the cytoplasm via the phenylpropanoid pathway, where PAL possesses a rate-limiting role. Wakabayashi et al. [27] reported a rapid increase in PAL activity during growth of wheat shoots under normal growth conditions, and a close correlation between the changes in the activity of PAL and the rate of increase in the amount of CW-bound FA. Also, Grabber et al. [8] found that in maize cell suspensions the use of a specific inhibitor of PAL substantially decreased the level of CW-bound FA.

Based on these facts, both CW-bound FAPOD and PAL activities were investigated assuming that both might have a crucial role in the regulation of the formation of FA network.

The activity of the CW-ionically bound FAPOD, showed a gradual increase in control basal segments. This activity reached its higher value at day 13 coinciding with the maximum deposition of both FA and DFA (Figure 6(a) and Figure 3). Therefore, the formation of DFA appeared to begin at about the time CW FAPOD activity reached a value ca. $0.028 \mathrm{nkat} \cdot \mathrm{g} \cdot \mathrm{DW}^{-1}$ (Figure 6(a)). Apical control segments showed a constant value lower than $0.010 \mathrm{nkat} \cdot \mathrm{g} \cdot \mathrm{DW}^{-1}$ through all the sampling interval time (Figure 6(b)). It is worthy to note that no DFA was found in this kind of segments. A transient increase in apoplastic peroxidase was reported preceding cessation of segmental elongation in tall fescue [28] and in maize [29]. Also the same gradual increase in CW bound FAPOD activity was found in A. brasilense-inoculated basal segments that reached its higher value at day 13 coinciding with their own maximum deposition of DFA. Gibberellins are believed to lower the apoplastic peroxidase activity and thus encourage cell elongation leading to cell expansion [29]. On the other hand, azospirilla are able to produce and secrete plant growth regulators (phytohormones) such as auxins, cytokinins, and gibberellins [1]. The constitutive initiation of cross-linking might be related to the disappearance of an inhibitor/ growth regulator, or the increased production of hydrogen peroxide, or both. Further work is however required to clarify these points.

With respect to PAL activity, it has been shown that environmental factors and pathogens modify the level of CW-bound FA via affecting the PAL activity in some gramineous shoots [30]. The raise detected in these conditions reached almost a $60 \%$ with respect to a non-infected or non-stressed control [30]. Fallik et al. [31] demonstrated that Azospirillum does not behave as a pathogenic rhizosphere bacterium, and that inoculation did not affect the activity of PAL. Here the 15\% increase in PAL activities observed (Figure 7(a), Figure 7(b)) did not result in higher extractable FA, DFA and p-coumarate contents (Figure 2(a), Figure 2(b), Figure 3, and Figure 4(a), Figure 4(b)). As the phenylpropanoid pathway also derives in other important phenolic metabolic intermediates, the higher PAL activity might be indicating that $A$. brasilense treatment could be activating these alternative metabolisms [15] and not triggering a pathogenic process as it is well established for azospirilla [31].

\section{Conclusions}

The control of plant growth is of enormous importance in agriculture. So, the mechanisms operating in the CW 
are intensively and actively investigated [32]. The CW does much more than provide strength and shape. It provides a ready path for the movement of some materials, parallel to the cell surface. The walls of neighboring cells are in direct contact, and so the plant's CW combines to form a major transport pathway, the apoplast. The constraints posed by the CW seem to have influenced the choice of cell-signaling molecules in plants. Most of them are small and either neutral or negatively charged, in contrast to the positively charged hormones in animal systems. The variety of roles the CW fulfils goes far to explain the architectural complexity which is now being revealed in the wall by modern analytical techniques. This complexity means that CW structure, and hence also CW biosynthesis must be under close control.

This paper demonstrates for the first time, that very young Azospirillum inoculated-seedlings grown in the dark have a different CW structure, overriding this close control. It also shows that the apoplast of inoculated seedlings has a different composition, and so the signals derived from it, would send different biochemical messages.

It was previously reported that the CW was a target for A. brasilense growth promotion. This work corroborates that the phenolics, FA, DFA, and p-coumarate bound to the CW, and their related enzymes are also involved in Azospirillum plant growth promoting properties.

\section{Methods}

\subsection{Cucumber Inoculation and Colonization Assessment}

A. brasilense Sp245 was cultured for inoculation as previously described [2]. Cell suspension concentrations were calculated from Most Probable Number determined in Nitrogen Free broth media by triplicate [33] and related to the optical density determined at $600 \mathrm{~nm}$. Cucumis sativus cv. Dasher II seeds were disinfected in $1 \%$ $\mathrm{NaClO}$ for $3 \mathrm{~min}$, thoroughly rinsed in sterile water, and germinated on wet filter paper in sealed trays incubated in the dark at $25^{\circ} \mathrm{C} \pm 1^{\circ} \mathrm{C}$ for $24 \mathrm{~h}$. Pre-germinated seeds were submerged in a $10^{6} \mathrm{~A}$. brasilense cells $\mathrm{mL}^{-1}$ in 66 $\mathrm{mM}$ phosphate buffer ( $\mathrm{pH}$ 6.8) for $2 \mathrm{~h}$ as previously described [2]. Control seeds were submerged in $66 \mathrm{mM}$ phosphate buffer (pH 6.8). After these treatments seedlings were grown in the dark at $25^{\circ} \mathrm{C} \pm 1^{\circ} \mathrm{C}$ and samples were taken at $8,10,13$, and $15 \mathrm{~d}$. All manipulations were done under dim green light. Roots were excised from seedlings, then $1 \mathrm{~g}$ FW (c.a. $0.1 \mathrm{~g}$ DW) were used to quantify bacterial root colonization through Most Probable Number determination [33] as described earlier [2].

\subsection{Cucumber Growth Responses to A. brasilense Inoculation}

At each sampling time and prior to destructive sampling, hypocotyl length was determined manually by means of a ruler on 150 individual seedlings per treatment. Growth promotion \% was calculated from A. brasilensetreated hypocotyl length (AL) and control non-inoculated hypocotyl length (CL), as follows:

$$
\text { Growth promotion } \%=(\mathrm{AL}-\mathrm{AC}) * 100 / \mathrm{AC} \text {. }
$$

\subsection{Extraction and Analysis of CW-Bound Phenolic Compounds}

At each sampling time, elongating hypocotyls were detached from the seedling, and $2 \mathrm{~cm}$-long basal and apical segments were taken starting from the seed junction or $3 \mathrm{~mm}$ below the apical tip, respectively. Cell wall-bound phenolics were extracted according to the method described by [17] with slight modifications. Briefly, $0.2 \mathrm{~g}$ DW of each pooled hypocotyl segment tissue was crushed in liquid nitrogen, then extracted with methanol/distilled water $(80 / 20, v / v)$ and absolute ethanol consecutively, and finally centrifuged at $930 \times \mathrm{g}$ for $10 \mathrm{~min}$. The supernatant was discarded. The residue, used as source of $\mathrm{CW}$ bound phenolics, was subjected to alkaline hydrolysis using $1 \mathrm{M}$ sodium hydroxide for $18 \mathrm{~h}$ in the dark, following the same method as described by [18]. This saponified extract was acidified with hydrochloride acid (pH $1-2)$, and subsequently extracted with $7 \mathrm{~mL}$ of ethyl acetate. The organic fraction was evaporated to dryness under nitrogen flow. Known quantities of t-cinnamic acid were added previous saponification in recuperation essays.

High pressure liquid chromatography (HPLC) analysis of FA, DFA and p-coumarate was performed as described by [18] with slight modifications. Samples were analyzed by HPLC on a Hewlett Packard 1100 HPLC system equipped with a binary pump fitted with a Phenomenex reverse phase LUNA C-18 $(250 \mathrm{~mm} \times 4.6 \mathrm{~mm}, 5$ $\mu$ ) column, temperature control unit, and a photo-diode array UV detector. Loads: $20 \mu \mathrm{L}$. Elution with a ternary 
system of solvents [A] acetonitrile/aq. trichloroacetic acid (TCA) $1 \mathrm{mM}(10 / 90, \mathrm{v} / \mathrm{v})$, [B] methanol/TCA $1 \mathrm{mM}$ $(80 / 20, \mathrm{v} / \mathrm{v})$, and [C] acetonitrile/TCA $1 \mathrm{mM}(80 / 20, \mathrm{v} / \mathrm{v})$, under gradient conditions percentage from 90/5/5 over $25 \mathrm{~min}$ followed by 25/37/37 for $5 \mathrm{~min}$, then 0/50/50 for $15 \mathrm{~min}$ and re-equilibration of the column to the initial gradient for $10 \mathrm{~min}$. Preliminary identification was achieved at 280 and $325 \mathrm{~nm}$ by comparing the retention times and the chromatographic behaviors with those from authentic standards. p-hidroxibenzoic acid was used as the internal standard. To minimize variation in quantification, three different samples were taken in triplicate and three injections were conducted using the same sample. The area variation was below $10 \%$ for all the integrated peaks. Ferulate contents were expressed as $\mathrm{mg} \cdot \mathrm{g} \cdot \mathrm{DW}^{-1}$.

\subsection{FAPOD Assays}

Similar hypocotyl samples taken as described above were immediately frozen in liquid nitrogen. They were then processed to obtain CW ionically bound peroxidases as described by [34]. Briefly, $1 \mathrm{~g} \mathrm{FW}$ apical or basal tissue was homogenized in a cold mortar with pestle along with $1 \%$ polyvinyl pyrrolidone in $50 \mathrm{mM}$ phosphate buffer (pH 5.8). The homogenate was centrifuged at $2830 \times \mathrm{g}$ for $15 \mathrm{~min}$ at $4^{\circ} \mathrm{C}$ and then washed four times with the buffer solution. The final pellet was resuspended in $1 \mathrm{M} \mathrm{NaCl}$ for $2 \mathrm{~h}$ at $20^{\circ} \mathrm{C}$ and finally filtered. This last supernatant was used as protein extract for peroxidase activity. Ferulate POD activity was assayed according to [35]. The decrease in FA concentration was measured in a Smart Spec 3000-Bio Rad spectrophotometer following the absorbance decrease at $310 \mathrm{~nm}$ for $4 \mathrm{~min}$ in a reaction mixture containing $1.35 \mathrm{~mL} 0.2 \mathrm{M}$ phosphate buffer (pH 5.8), $0.5 \mathrm{~mL} 240 \mathrm{mM} \mathrm{FA}, 0.5 \mathrm{~mL} 3 \mathrm{mM} \mathrm{H}_{2} \mathrm{O}_{2}$, and $0.15 \mathrm{~mL}$ enzyme extract. Ferulate POD activity was expressed as nkat.g. $\mathrm{DW}^{-1}$.

\subsection{PAL Assays}

Hypocotyl samples taken as described above were immediately frozen in liquid nitrogen. Enzyme extraction steps were carried out at $4^{\circ} \mathrm{C}$. One g FW of each pooled segment tissue was crushed in liquid nitrogen in presence of $1 \%(\mathrm{w} / \mathrm{w})$ polyvinyl pyrrolidone, and then extracted with $4 \mathrm{ml}$ of $100 \mathrm{mM}$ Tris-HCl buffer (pH 8.5) supplemented with $10 \mathrm{mM}$ EDTA, and $0.08 \mathrm{mM} \beta$-mercaptoetanol [36]. The suspension was homogenized for 1 min and then centrifuged at $2830 \times \mathrm{g}$ for $20 \mathrm{~min}$ at $4^{\circ} \mathrm{C}$. PAL was assayed directly in the supernatant [36] after passing it through a $0.45 \mu \mathrm{m}$ membrane (Millipore, Bedford, USA). $100 \mathrm{mM}$ Tris- $\mathrm{HCl}$ (pH 8.5) was used as assay buffer. The formation of t-cinnamic acid was measured in a Smart Spec 3000-Bio Rad spectrophotometer at $290 \mathrm{~nm}$ after $1 \mathrm{~h}$ of incubation at $37^{\circ} \mathrm{C}$ of a reaction mixture containing $700 \mu \mathrm{l} 100 \mathrm{mM}$ Tris-HCl buffer (pH 8.5), $1800 \mu \mathrm{l} 6 \mu \mathrm{M}$ phenylalanine, and $500 \mu \mathrm{l}$ of enzyme extract. t-cinnamic acid content was calculated using the extinction coefficient value of $9630 \mathrm{M} \cdot \mathrm{cm}^{-1}$ [30]. PAL activity was expressed as nkat $\cdot \mathrm{g} \cdot \mathrm{DW}{ }^{-1}$.

\subsection{Experimental Design and Statistical Analysis of Data}

The experiments were a factorial combination of two inoculation levels (with and without bacteria) and four times $(8,10,13$ and $15 \mathrm{~d})$ in complete randomized blocks, with three replicas in time and applied independently in apical or basal segments. One hundred and fifty hypocotyls were analyzed in each treatment for growth response determination. Collected apical or basal segment material was randomly divided into three $0.2 \mathrm{~g} \mathrm{DW}$ pools and analyzed. Three independent replicates of $1.0 \mathrm{~g} \mathrm{FW}$ each were analyzed in each treatment either in FAPOD or PAL activity assays. The results were analyzed through PROC GLM procedure using SAS statistical package SAS [37]. Significance levels $(\mathrm{P}<0.05)$ were determined through ANOVA and Tukey's test.

\section{Acknowledgements}

We thank Ms. Silvia Alicia Larraburu for technical help at the laboratory, and Ing Peter Daniel for assistance with HPLC techniques. This study was supported by funds from the Universidad Nacional de Mar del Plata (UNMdP), Argentina.

\section{References}

[1] Fibach-Paldi, S., Burdman, S. and Okon, Y. (2012) Key Physiological Properties Contributing to Rhizosphere Adaptation and Plant Growth Promotion Abilities of Azospirillum brasilense. FEMS Microbiology Letters, 326, 99-108. http://dx.doi.org/10.1111/j.1574-6968.2011.02407.x 
[2] Creus, C., Sueldo, R. and Barassi, C. (1998) Water Relations in Azospirillum-Inoculated Wheat Seedlings under Osmotic Stress. Canadian Journal of Botany, 76, 238-244. http://dx.doi.org/10.1139/b97-178

[3] Creus, C., Sueldo, R. and Barassi, C. (2004) Water Relations and Yield in Azospirillum-Inoculated Wheat Exposed to Drought in the Field. Canadian Journal of Botany, 82, 273-281. http://dx.doi.org/10.1139/b03-119

[4] Pereyra, C., Ramella, N., Pereyra, M., Barassi, C. and Creus, C. (2010) Changes in Cucumber Hypocotyl Cell Wall Dynamics Caused by Azospirillum brasilense Inoculation. Plant Physiology and Biochemistry, 48, 62-69. http://dx.doi.org/10.1016/j.plaphy.2009.10.001

[5] Belfield, E., Ruperti, B., Roberts, J. and McQueen-Mason, S. (2005) Changes in Expansion Activity and Gene Expression during Ethylene-Promoted Leaflet Abscission in Sambucus nigra. Journal of Experimental Botany, 56, 817-823. http://dx.doi.org/10.1093/jxb/eri076

[6] Carpita, N. (1996) Structure and Biogenesis of the Cell Walls of Grasses. Annual Review of Plant Physiology and Plant Molecular Biology, 47, 445-476. http://dx.doi.org/10.1146/annurev.arplant.47.1.445

[7] Fry, S. (1986) Cross-Linking of Matrix Polymers in the Growing Cell Walls of Angiosperms. Annual Review of Plant Physiology and Plant Molecular Biology, 37, 165-186. http://dx.doi.org/10.1146/annurev.pp.37.060186.001121

[8] Grabber, J., Hartfield, R., Ralph, J., Zon, J. and Amrhein, N. (1995) Ferulate Cross-Linking in Cell Walls Isolated from Maize Cell Suspensions. Phytochemistry, 40, 1077-1082. http://dx.doi.org/10.1016/0031-9422(95)00413-2

[9] Fry, S. (2004) Oxidative Coupling of Tyrosine and Ferulic Acid Residues: Intra- and Extra-Protoplasmic Occurrence, Predominance of Trimers and Larger Products, and Possible Role in Inter-Polymeric Cross-Linking. Phytochemistry Reviews, 3, 97-111. http://dx.doi.org/10.1023/B:PHYT.0000047808.74647.43

[10] Tan, K., Hoson, T., Masuda, Y. and Kamisaka, S. (1992) Effect of Ferulic and p-Coumaric Acids on Oryza coleoptile Growth and the Mechanical Properties of Cell Walls. Journal of Plant Physiology, 140, 460-465. http://dx.doi.org/10.1016/S0176-1617(11)80825-4

[11] Wakabayashi, K., Hoson, T. and Kamisaka, S. (1997) Osmotic Stress Suppresses the Cell Wall Stiffening and the Increase in Cell Wall-Bound Ferulic and Diferulic Acids in Wheat Coleoptiles. Plant Physiology, 113, 967-973.

[12] Kawamura, Y., Wakabayashi, K., Hoson, T., Yamamoto, R. and Kamisaka, S. (2000) Stress Relaxation Analysis of Submerged and Air-Grown Rice Coleoptiles: Correlations with Cell Wall Biosynthesis and Growth. Journal of Plant Physiology, 156, 689-694. http://dx.doi.org/10.1016/S0176-1617(00)80233-3

[13] Vailhé, M., Provan, G., Scobbie, L., Chesson, A., Maillot, M., Cornu, A. and Besle, J. (2000) Effect of Phenolic Structures on the Degradability of Cell Walls Isolated from Newly Extended Apical Internode of Tall Fescue (Festuca arundinacea Schreb.). Journal of Agricultural and Food Chemistry, 48, 618-623. http://dx.doi.org/10.1021/jf9906329

[14] Passardi, F., Cosio, C., Penel, C. and Dunand, C. (2005) Peroxidases Have More Functions than a Swiss Army Knife. Plant Cell Reports, 24, 255-265. http://dx.doi.org/10.1007/s00299-005-0972-6

[15] Rohde, K., Ralph, J., Goeminne, G., Hostyn, V., De Rycke, R., Kushnir, S., Doorsselaere, J., Vuylsteke, M. and Gonzales Van Driessche, Van Beeumen, J., Messens, E., Boerjan, W. (2004) Molecular Phenotyping of the pal1 and pal2 Mutants of Arabidopsis thaliana Reveals Far-Reaching Consequences on Phenylpropanoid, Amino Acid and Carbohydrate Metabolism. The Plant Cell, 16, 2749-2771. http://dx.doi.org/10.1105/tpc.104.023705

[16] Parvez, M., Wakabayashi, K., Hoson, T. and Kamisaka, S. (1997) White Light Promotes the Formation of Diferulic Acid in Maize Coleoptile Cell Walls by Enhancing PAL Activity. Physiologia Plantarum, 99, 39-48. http://dx.doi.org/10.1111/j.1399-3054.1997.tb03428.x

[17] Locher, R., Martin, H., Grison, R. and Pilet, P. (1994) Cell Wall-Bound trans and cis-Ferulic Acids in Growing Maize Roots. Physiologia Plantarum, 90, 734-738. http://dx.doi.org/10.1111/j.1399-3054.1994.tb02531.x

[18] Waldron, K., Parr, A., Ng, A. and Ralph, J. (1996) Cell Wall Esterified Phenolic Dimers: Identification and Quantification by Reverse Phase High Performance Liquid Chromatography and Diode Array Detection. Phytochemical Analysis, 7, 305-312. http://dx.doi.org/10.1002/(SICI)1099-1565(199611)7:6<305::AID-PCA320>3.0.CO;2-A

[19] Grabber, J., Ralph, J. and Hatfield, R. (2000) Cross-Linking of Maize Walls by Ferulate Dimerization and Incorporation into Lignin. Journal of Agricultural and Food Chemistry, 48, 6106-6113. http://dx.doi.org/10.1021/jf0006978

[20] Obel, N., Porchia, A. and Scheller, H. (2002) Dynamic Changes in Cell Wall Polysaccharides during Wheat Seedling Development. Phytochemistry, 60, 603-610. http://dx.doi.org/10.1016/S0031-9422(02)00148-6

[21] Welinder, K. (1992) Plant Peroxidases: Structure-Function Relationships. In: Penel, C., Gaspar, T. and Greppin, H., Eds., Plant Peroxidases, University of Geneva, Geneva, 1-24.

[22] McDougall, G. (1992) Changes in Cell Wall-Associated Peroxidases and Lignification during Growth of Flax Fibers. Phytochemistry, 31, 3385-3389. http://dx.doi.org/10.1016/0031-9422(92)83691-Q

[23] Pedreño, M., Ferrer, M., Gaspar, T., Muñoz, R. and Ros Barcelo, A. (1995) The Polyfunctionality of Cell Wall Peroxidases Avoids the Necessity of an Independent $\mathrm{H}_{2} \mathrm{O}_{2}$-Generating System for Phenolic Coupling in the cell Walls. Plant 
Peroxidase Newsletter, 5, 3-8.

[24] González, L., Rojas, M. and Pérez, F. (1999) Diferulate and Lignin Formation Is Related to Biochemical Differences of Wall-Bound Peroxidases. Phytochemistry, 50, 711-717. http://dx.doi.org/10.1016/S0031-9422(98)00611-6

[25] Encina, A. and Fry, S. (2005) Oxidative Coupling of a Feruloyl-Arabinoxylan Trisaccharide (FAXX) in the Walls of Living Maize Cells Requires Endogenous Hydrogen Peroxide and Is Controlled by a Low-M Apoplastic Inhibitor. Planta, 223, 77-89. http://dx.doi.org/10.1007/s00425-005-0033-y

[26] Burr, S. and Fry, S. (2009) Extracellular Cross-Linking of Maize Arabinoxylans by Oxidation of Feruloyl Esters to Form Oligoferuloyl Esters and Ether-Like Bonds. The Plant Journal, 58, 554-567. http://dx.doi.org/10.1111/j.1365-313X.2009.03800.x

[27] Wakabayashi, K., Soga, K. and Hoson, T. (2012) Phenylalanine Ammonia-Lyase and Cell Wall Peroxidase Are Cooperatively Involved in the Extensive Formation of Ferulate Network in Cell Walls of Developing Rice Shoots. Journal of Plant Physiology, 169, 262-267. http://dx.doi.org/10.1016/j.jplph.2011.10.002

[28] MacAdam, J., Sharp, R. and Nelson, C. (1992) Peroxidase Activity in the Leaf Elongation Zone of Tall Fescue. Plant Physiology, 99, 879-885. http://dx.doi.org/10.1104/pp.99.3.879

[29] De Souza, I. and MacAdam, J. (2001) Gibberellic Acid and Dwarfism Effects on the Growth Dynamics of B73 Maize (Zea mays L.) Leafblades: A Transient Increase in Apoplastic Peroxidase Activity Precedes Cessation of Cell Elongation. Journal of Experimental Botany, 52, 1673-1682. http://dx.doi.org/10.1093/jexbot/52.361.1673

[30] Fallahzadeh, V., Ahmadzadeh, M., Marefat, A. and Ghazanfary, K. (2009) Application of Rhizobacteria for Induction of Systemic Resistance to Bacterial Blight of Cotton Caused by Xanthomonas campestris PV. Malvacearum Using Fluorescent Pseudomonads of Rhizosphere. Journal of Plant Protection Research, 49, 416-420. http://dx.doi.org/10.2478/v10045-009-0066-5

[31] Fallik, E. and Okon, Y. (1988) The Effect of Azospirillum brasilense Inoculation on Metabolic Enzyme Activity in Maize Root Seedlings. Symbiosis, 6, 17-28.

[32] Ringli, C. (2010) Monitoring the Outside: Cell-Wall Sensing Mechanisms. Plant Physiology, 153, 1445-1452. http://dx.doi.org/10.1104/pp.110.154518

[33] Postgate, J. (1969) Viable Counts and Viability. In: Norris, J.R. and Ribbons, D.W., Eds., Methods in Microbiology, Academic Press Inc., New York, 611-628.

[34] Lin, C. and Kao, C. (2001) Abscisic Acid Induced Changes in Cell Wall Peroxidase Activity and Hydrogen Peroxide Level in Roots of Rice Seedlings. Plant Science, 160, 323-329. http://dx.doi.org/10.1016/S0168-9452(00)00396-4

[35] Sánchez, M., Peña, M., Revilla, G. and Zarra, I. (1996) Changes in Dehydrodiferulic Acids and Peroxidase Activity against Ferulic Acid Associated with Cell Walls during Growth of Pinus pinaster Hypocotyl. Plant Physiology, 111, 941-946.

[36] Mitra, A., Mayer, M., Mellon, F., MichaeI, A., Narbad, A., Parr, A., Waldron, K. and Walton, N. (2002) 4-Hidro-xycinnamoyl-CoA Hydratase/Lyase, an Enzime of Phenylpropanoid Cleavage from Pseudomonas, Causes Formation of $\mathrm{C}_{6}-\mathrm{C}_{1}$ Acid and Alcohol Glucose Conjugates When Expressed in Hairy Roots of Datura stramonium L. Planta, 215, 79-89. http://dx.doi.org/10.1007/s00425-001-0712-2

[37] The SAS System for Windows (2000) Release 6.10. SAS Institute Inc., Cary, USA. 


\section{Abbreviations}

AL: A. brasilense-treated hypocotyl length;

CL: control non-inoculated hypocotyl length; CW: cell wall;

DFA: dehydrodiferulates;

DW: dry weight;

FA: ferulate;

FAPOD: ferulate peroxidase;

FW: fresh weight;

HCAs: hydroxycinammic acids;

HPLC: high pressure liquid chromatography;

PAL: phenyl alanine ammonia lyase;

PGPR: plant growth promoting rhizobacteria;

TCA: trichloroacetic acid. 